Journal of Social Sciences 6 (1): 123-126, 2010

ISSN 1549-3652

(C) 2010 Science Publications

\title{
Patriarchy and Women's Gender Ideology: A Socio-Cultural Perspective
}

\author{
A.M. Sultana \\ Department of Malaysian Studies, Faculty of Social Sciences and Humanities, \\ University Pendidikan Sultan Idris, 35900 Tanjong Malim, Perak, Malaysia
}

\begin{abstract}
Problem statement: This research was designed to examine women's gender ideology in educating their children. It attempts to understand women's gender ideology as articulated by the women themselves based upon their own point of view. The study highlights that patriarchal norms has an influence on women's attitudes regarding their privilege rights and responsibilities towards educating children. Women's gender ideology appears to be constrained by patriarchal ideology that give priority to the masculine over the feminine in almost all environments, that is to say school, household, labor market and community. Due to patriarchal belief, parents give less priority on daughter's education. Approach: The objectives of this research are (a) to determine women's gender ideology concerning children's education; (b) to examine the influence of patriarchal norms on women's gender ideology. Results: Employing detailed descriptive quantitative results, the work suggests that in Bangladesh most of rural women tended to follow traditional ideology regarding daughter's education. Conclusion: The study was conducted in one of the districts of Dinajpur in Bangladesh. Three villages namely Mashimpur, Mohiskotha and Jugibari which are situated under the Union of Auliapur at Sadar thana (sub-district) were chosen as study areas. The respondents of the study consisted of 340 women from the selected areas.
\end{abstract}

Key words: Gender ideology, patriarchal norms, gender relation, traditional ideology, socio-cultural norms

\section{INTRODUCTION}

The main aim of the article is to examine women's gender ideology concerning daughter's education among the rural communities of Bangladesh. In a society, gender ideology is created and reflected in multiple ways (Hussein, 2004). Feminist theory maintains that stronger patriarchal attitudes in a society are linked with higher level of prevalence of male dominance towards women in society (Brownridge, 2002). For measuring patriarchal ideology of gender relations, most of researchers commonly used an accumulative index of multiple dimensions of gender relations like extent of adherence to the conventional ideas about gender inequality, rigid segregation of gender roles, male dominance against women (Ali and Khan, 2007; Olson, 2004). In Bangladesh, gender ideology appears to be constrained by patriarchal ideology that give priority to the masculine over the feminine in almost all environments, that is to say school, household, labor market and community. Bangladeshi society has been portrayed as a typical example of patriarchy, where male superiority is accepted as part of the natural order of things and women are relatively powerless in the public sphere and, to a less extent, in the private sphere too. Men are considered to be economic producers while women are regarded as reproducers who are dependent on men. Like other patriarchal societies, in Bangladeshi society, men have greater power and authority simply by virtue of being men and therefore 'head' of the family (Schuler et al., 1996). Thus, women's gender ideology is viewed against the backdrop of 'patriarchy', which enables men to dominate women. This can be viewed in household relations (Naved, 1994; Hashemi et al., 1996). However, there is no denying to the fact that in Bangladesh, most of women are cultural dominated and more likely to follow traditional ideology. Women's ideology is affected by the patriarchal ideology. Therefore, women's gender ideology appears to be constrained by patriarchal ideology that gives priority to son's education over daughter's education. Research on this issue in Bangladesh is still incipient. Most of the existing studies have been based on indepth interviews of a small number of urban women. The present study is based on interviews of a large number of rural women.

Objectives of the study: The objectives of this article are (1) to examine women's gender ideology and 
perception about their children's education and (2) to identify patriarchal ideology that might affect on women gender ideology.

\section{MATERIALS AND METHODS}

The study is based on primary information. The paper uses structured survey data from the selected study areas. The findings presented in this study are based on survey research by the researcher in three villages in north region of Bangladesh between 2008 and 2009 and a purposive sampling survey of about 340 women. The respondents for this study were selected based on three criteria. Firstly, the respondent must be a married woman. Secondly, the respondent must have at least two children. Thirdly, these must be at least one son and one daughter.

Research design: One-shot cross-sectional survey research design was employed in this article. The research was a non-probability sampling. The principle researcher had selected two research assistants who had previous experienced in conducting demographic surveys. The survey included questions related to women's roles and responsibilities, about the role of education. A total of 340 married women were interviewed.

Data analysis: In this article, a Likert scale has been used to examine respondent's gender ideology regarding the value of women's education. The variables of respondent's gender ideology of education were measured using 8 items on a four point Likert format. In this format the responses were carried out in term of agree, strongly agree, disagree and strongly disagree are presented the values of 1-4 respectively. In response to each of the items, respondents made their ratings on a four point scale, pointing whether they (1) strongly agree (2) agree (3) disagree and (4) strongly disagree. From a socio-cultural perspective, respondent's attitudes were classified as 'traditional ideology' and 'non-traditional gender ideology'. For these classifications, the article adopted the concept of Linder et al. (1995) and Matthews and Beaugot (1997). The total 8 statements were analyzed with frequencies with eight items. In order to examine gender awareness of women, a total of eight variables were constructed summing all the values of the eight variables for each respondent.

\section{RESULTS}

The study measured respondent's gender ideology and awareness regarding children's education using a four point Likert scale. The respondent's gender ideology was examined using a set of statements that reflect respondent's attitudes towards their expectation and responsibilities towards their children's education. The respondent's values and beliefs are an important factor in determining patriarchal influence that reflects women's ideology. To examine respondent's gender ideology, 8 items statements were constituted and the results are shown in Table 1.

Table 1: Women gender ideology regarding children's education

\begin{tabular}{|c|c|c|c|c|c|c|c|c|c|c|}
\hline \multirow[b]{3}{*}{ Variables } & \multicolumn{10}{|c|}{ Attitude of respondent's regarding education } \\
\hline & \multicolumn{2}{|c|}{ Strongly agree } & \multicolumn{2}{|c|}{ Agree } & \multicolumn{2}{|c|}{ Disagree } & \multicolumn{2}{|c|}{$\begin{array}{l}\text { Strongly } \\
\text { disagree }\end{array}$} & \multicolumn{2}{|l|}{ Total } \\
\hline & $\mathrm{N}$ & $(\%)$ & $\mathrm{N}$ & $(\%)$ & $\mathrm{N}$ & $(\%)$ & $\mathrm{N}$ & $(\%)$ & $\mathrm{N}$ & $(\%)$ \\
\hline $\begin{array}{l}\text { Daughter should not to pursue higher } \\
\text { education, but son should do so. }\end{array}$ & 138 & 40.6 & 90 & 26.5 & 58 & 17.1 & 54 & 15.90 & 340 & 100 \\
\hline $\begin{array}{l}\text { Daughter's education is less important than } \\
\text { son as son contribute family income. }\end{array}$ & 194 & 57.1 & 36 & 10.6 & 56 & 16.5 & 54 & 15.90 & 340 & 100 \\
\hline $\begin{array}{l}\text { Access to basic education is human rights for } \\
\text { boys only. }\end{array}$ & 38 & 11.0 & 65 & 19.1 & 184 & 54.1 & 53 & 15.59 & 340 & 100 \\
\hline $\begin{array}{l}\text { Education is more important for boys } \\
\text { than the girls. }\end{array}$ & 175 & 51.5 & 52 & 15.3 & 52 & 15.3 & 61 & 17.90 & 340 & 100 \\
\hline $\begin{array}{l}\text { The role and duty of women is to taking care of } \\
\text { the children and the household only. }\end{array}$ & 184 & 54.1 & 42 & 12.6 & 59 & 17.4 & 55 & 16.20 & 340 & 100 \\
\hline $\begin{array}{l}\text { Parents should to be given high value to son's } \\
\text { education because they are potential providers } \\
\text { and perpetrators of family names. }\end{array}$ & 150 & 44.2 & 76 & 22.4 & 59 & 17.4 & 55 & 16.20 & 340 & 100 \\
\hline $\begin{array}{l}\text { Girls should be given priority on training the } \\
\text { domestic chores rather than to their education. }\end{array}$ & 193 & 56.8 & 36 & 10.6 & 57 & 16.8 & 54 & 15.90 & 340 & 100 \\
\hline $\begin{array}{l}\text { Parents should to give less priority on daughters' } \\
\text { education because they will go away another } \\
\text { house after marriage. }\end{array}$ & 202 & 59.4 & 32 & 9.4 & 59 & 17.4 & 47 & 13.80 & 340 & 100 \\
\hline
\end{tabular}


The results show that $40.6 \%$ of the respondents are referred as 'agreed' and $26.5 \%$ respondents are as 'strongly agreed' for the first statement. On the other hand, 17.1 and $15.9 \%$ of the respondents show 'disagreed' and 'strongly disagreed' respectively. Similar results were observed for the other statements.

\section{DISCUSSION}

The results presented in Table 1 show that majority of women performed traditional ideology which has been observed in the first statement. Majority of respondents agreed that daughter should not pursue higher education but son should to do. The results indicate that the majority of the respondents tended to follow the traditional ideology as they do not like to support daughters' higher education. However, they believed that son should pursue higher education. Indeed to say that due to patriarchal ideology, sons are preferred than daughter to pursue higher education. Similarly, the majority (57.1 and 10.6\%) of the respondents agreed and strongly agreed when they were asked to provide their opinion on the statement "daughter's education is less important than son as son will contribute to family income". These results indicate that the majority of the respondents tended to follow traditional ideology. In fact, the majority of the respondents are more closely linked with the culture.

The results for the third statement, "access to basic education is human rights for boys only" have been considered as the liberal ideology as majority of women $(54.1$ and $15.5 \%)$ disagreed on it. These results are considered as liberal as well as non-traditional ideology and the majority of the respondents tended to follow the liberal ideology regarding basic education for their children. Although liberal ideology has been observed about the basic education, most of respondents tended to follow traditional ideology when they were asked to give their opinion in the statement, "the role and duty of women is to taking care of the children and the household only" majority of respondents (54.1 and $12.60 \%$ ) agreed and strongly agreed respectively. These results reveal that the majority of the women believed that the role and duty of women is to taking care of children and household only. These results is not surprising in a patriarchal society like Bangladesh, where men's superior status leading to power over women and dominant status by religious, traditional, moral and/or pseudo-scientific ideologies and beliefs. Traditionally, the roles of women are considered to be as a daughter, wife and a mother. In Bangladesh it is considered that women's function is to give birth to the babies, nurse them up and manage the household.
Women's work and lives take place within the sheltered confines of the extended household and compound.

For the last three statements, it was observed that the typical patriarchal ideology can be seen especially when respondents were asked to give their opinion in the statement "parents should to give high value to son's education because they are perpetrator to the family name", majority of women (44.2 and 22.4\%) agreed on it. From the results, it can be said that due to patriarchy son preference is well known in Bangladeshi culture. It is commonly believed that sons are more able to provide support to the parents in their old age. They also believe that sons maintain and extend the lineage, inherit family property and perpetrators to the family name. Similar patriarchal ideologies can be noticed for the rest of statements. The results of the last statement indicate that majority of the respondents agreed to give less priority to their daughter's education as she will go away to another house after marriage. On the other hand, boys are considered to be responsible for parental well-being, therefore, investment in them is seen as a rational decision and cultural practices that reinforce the 'giving away' of girls at marriage are likely to serve as a disincentive for educating daughters. A similar study has been conducted by Rose and Al-Samarrai (2001) in Ethiopia and in India respectively and was suggested that in these countries boys are considered to be responsible for parental well-being, so investment in them is seen as a rational decision and cultural practices that reinforce the 'giving away' of girls at marriage are likely to serve as a disincentive for educating daughters.

\section{CONCLUSION}

The present study contributed to show that the majority of the respondents tended to traditional ideology regarding their daughter's education. A patriarchal ideology typically was observed in the majority of the respondent's attitudes. From the ininterview, it was also clear that most of mothers tended to traditional ideology about daughter's education. They always preferred their sons in education. Women's education is largely determined by patriarchal control which reflects gender-based inequalities in education. Due to patriarchal ideology less attention is paid to and less emphasis is placed on the education of girls and females than on that of boys and males. As a result, daughters in villages do not get the opportunity to acquire the same marketable skill and knowledge as the sons. Due to patriarchal ideology, a woman discriminates against another woman which limits women's education opportunity. 


\section{REFERENCES}

Ali, T.S. and N. Khan, 2007. Strategies and recommendations for prevention and control of domestic violence against women in Pakistan. J. Pak. Med. Assoc., 57: 27-32. http://jpm.org.pk/full_article_text.php?article_id=1 042

Brownridge, D.A., 2002. Cultural variation in male partner violence against women: A comparison of Quebec with the rest of Canada. Violence Against Women, 8: 87-115. DOI: 10.1177/107780120200800105

Hashemi, S., S.R. Schuler and A.P. Riley, 1996. Rural credit programs and women's empowerment in Bangladesh. World Dev., 24: 635-653. http://ideas.repec.org/a/eee/wdevel/v24y1996i4p63 5-653.html

Hussein, J. W., 2004. A cultural representation of women in the Oromo society. Afr. Study Monogr., 25: 103-147. http://www.africa.kyotou.ac.jp/kiroku/asm-normal/abstracts/pdf/25-3/25-31.pdf

Linder, M.A., R.M. Ryckman, J.A. Gold and W.F. Stone, 1995. "Traditional Vs non-traditional women and men's perceptions of the personalities and physiques of ideal women and men. Sex Roles, 32: 675-690. DOI: 10.1007/BF01544218
Matthews, B. and R. Beaugot, 1997. Gender orientation and family strategies. Can. Rev. Sociol. Anthropol., 34: 415-425. DOI: 10.1111/j.1755618X.1997.tb00217.x

Naved, R., 1994. Empowerment of women: Listening to the voices of women. Bangladesh Dev. Stud., 22: $\quad$ 121-155. http://www.bidsbd.org/BDS.php?FM=6\&SM=\&75\&TM=103\&Pag $\mathrm{e}=\mathrm{BDS}$

Olson, L.N., 2004. Relational control-motivated aggression: A theoretically-based typology of intimate violence. J. Fam. Commun., 4: 209-233. DOI: $10.1207 / \mathrm{s} 15327698 j \mathrm{jc} 0403 \& 4 \_7$

Rose, P. and S. Al-Samarrai, 2001. Household constraints on schooling by gender: Empirical evidence from Ethiopia. Comparat. Educ. Rev., 45: 36-63. DOI: 10.1086/447644

Schuler, S.R., S.M. Hashemi, A.P. Riley and S. Akhter, 1996. Credit programs, patriarchy and men's violence against women's in rural Bangladesh Soc. Sci. Med., 43: 1729-1742. DOI: 10.1016/S02779536(96)00068-8 